\title{
Produção científica docente: estudo sobre as publicações dos cursos de Jornalismo do Tocantins
}

Poliana Macedo de Sousa?

Resumo: $\bigcirc$ presente estudo faz um mapeamento da produção científica dos docentes vinculados aos cursos de Jornalismo no Estado do Tocantins, em três Instituições de Ensino Superior (Universidade Federal do Tocantins - UFT, Centro Universitário Unirg e Ceulp/Ulbra), todos credenciados pelo MEC Ministério da Educação e que estavam em funcionamento durante os anos de 2006 a 2016. Esse mapeamento foi realizado por meio de análise do Currículo Lattes de cada docente até então vinculado aos cursos. Analisou-se a publicação de artigos em periódicos, livros e/ou capítulos de livros publicados, trabalhos publicados em anais de eventos, resumos publicados em anais de eventos e apresentação de trabalhos em eventos científicos. Com esse mapeamento foi possível identificar o quanto os docentes produziram nesse período e qual o canal de comunicação científico mais utilizado pelos mesmos para a divulgação de sua produção científica.

Palavras-chave: Comunicação Científica. Produção Científica. Jornalismo.

\begin{abstract}
The present study mapped the scientific production of teachers to Journalism courses in the State of Tocantins, in three Higher Education Institutions (UFT, Unirg and Ceulp / Ulbra), all of which were accredited by MEC Ministry of Education and were in operation during the years of 2006 to 2016. This mapping was carried out by means of analysis of the Curriculum Lattes of each teacher that until then was linked to the courses. The publication of articles in periodicals, books and / or chapters of published books, papers published in annals of events, abstracts published in annals of events and presentation of papers in scientific events were analyzed. With this mapping it was possible to identify how much the teachers produced in that period and what the channel of scientific communication most used by them for the dissemination of their scientific production.
\end{abstract}

Keywords: Accreditation. Image. Environmental value. Specialized Journalism.

Resumen: El presente estudio hace un mapeamiento de la producción científica de los docentes vinculados a los cursos de Periodismo en el Estado de Tocantins, en tres Instituciones de Enseñanza Superior (Universidad Federal de Tocantins - UFT, Centro Universitario Unirg y Ceulp / Ulbra), todos acreditados por el MEC - Ministerio de la Educación y que estaban en funcionamiento durante los años de 2006 a 2016. Ese mapeamiento fue realizado por medio del análisis del Currículo Lattes de cada docente hasta entonces vinculado a los cursos. Se analizó la publicación de artículos en periódicos, libros y / o capítulos de libros publicados, trabajos publicados en anales de eventos, resúmenes publicados en anales de eventos y presentación de trabajos en eventos 
científicos. Con ese mapeamiento fue posible identificar cuánto los docentes produjeron en ese período y cuál es el canal de comunicación científico más utilizado por los mismos para la divulgación de su producción científica.

Palabras clave: Comunicación Científica. Producción Científica. Periodismo.

\section{Introdução}

Quando se fala (ou se lê) algo sobre produção científica, a primeira imagem que se associa a tal termo é a publicação de artigos científicos. Porém, a produção científica e sua consequente divulgação não se resumem apenas à publicação em periódicos.

Sabe-se ainda, que a produção científica é um dos pilares das universidades como bem explica Morais (1995, p. 21) citado por Pôrto Jr \& Sousa (2016, p. 10) que "as universidades devem ser lugares de investigação, documentação, criatividade e ensino". E que, além dos periódicos existem outras tipologias documentais dentro do ambiente acadêmico que também são "locais" para divulgação da produção científica como livros, anais de eventos dentre outros.

O objetivo deste artigo foi analisar onde os docentes e consequentemente, pesquisadores dos cursos de Jornalismo do Estado do Tocantins, publicam seus trabalhos científicos dentro das categorias estabelecidas pelo CNPq, via Currículo Lattes, sendo elas: Artigos, Livros/ Capítulos de Livros, Anais de Congresso (Trabalhos completos), Resumos em Congressos e Apresentação de Trabalhos. Além de mensurar a produção acadêmica dos docentes no período de 2006 a 2016, quando do funcionamento de três cursos: dois na capital Palmas e outro no interior, na cidade de Gurupi.

A pesquisa teve viés exploratório, sendo caracterizada como documental, estudo de caso procedimentos concomitantes e métodos mistos (CRESWELL, 2007). O universo da pesquisa foi constituído por 35 docentes dos cursos de Jornalismo das Instituições de Ensino Superior do Estado do Tocantins que ofertavam o curso, sendo elas: Universidade Federal do Tocantins (UFT), Centro Universitário UnirG e Centro Universitário Luterano de Palmas (Ceulp/Ulbra).

\section{Produção científica na área de ciências sociais aplicadas}

Cabe ao docente escolher qual "meio" é mais adequado para divulgar seus trabalhos na sua área de atuação. Portanto, o que seria a comunicação científica? E o modo de informar a produção da ciência por uma determinada universidade?

Souza (2008, p. 142) explica que

a comunicação científica está associada aos canais que transferem o conhecimento produzido no âmbito de um determinado grupo cujo saber, particularmente o de caráter especializado, é produzido sob determinadas estratégias de construção. Ainda que todo o saber seja originado a partir do vasto universo mental do senso comum quando sua produção está subordinada à aplicação de métodos, técnicas e instrumentos tidos como sustentadores operacionais de uma estratégia, ou metodologia globalmente conhecida como ciência, será então um conhecimento científico. Esse conhecimento gerado a partir do emprego da metodologia com que se faz a ciência será o resultado da consolidação e comunicação de um jeito de se construir o conhecimento, sendo tipificado por um instrumental próprio, capaz de ser determinado como um produto socialmente constituído: a Ciência. 
Há consenso que as diferentes áreas dão preferência para canais diferentes quando da publicação dos resultados de suas pesquisas. Atualmente, a quantidade de artigos publicados em periódicos científicos é utilizada como forma de mensurar e avaliar a quantidade de informações que um pesquisador divulga no meio científico, mas nem sempre, como o velho senso comum já normatizou, quantidade é sinônimo de qualidade.

Meadows (1999) citado por Mueller (2005) explica que essa relação entre qualidade e quantidade dificulta o estabelecimento de parâmetros para comparação:

Isso pressupõe que a produtividade é mais bem avaliada em termos de artigos publicados. Muitos pesquisadores de humanidades preferem, no entanto, publicar os resultados de suas pesquisas em formato de livro e não em periódicos. Isso provavelmente compensa o desequilíbrio em matéria de publicação, mas em quanto? Em termos brutos, quantos artigos equivalem a um livro? Do mesmo modo, os engenheiros orientam-se muitas vezes para o desenvolvimento de produtos e patentes. Como é que se pode comparar isso com artigos? A resposta simples é que não se pode, embora hajam sido feitas várias tentativas nesses sentido (por exemplo, estimativas empíricas igualam um livro a algo que varia de dois a seis artigos).

Mueller (2005) ressalta ainda que

[...] as pesquisas nas ciências normais ou experimentais, apesar das diferenças entre elas, são geralmente conduzidas por equipes, se apoiam em paradigmas universalmente aceitos e produzem artigos não muito longos, que são enviados para publicação prioritariamente em periódicos de circulação internacional e em língua inglesa. Nas áreas classificadas como ciências sociais e humanidades, ao contrário, as pesquisas, de modo geral, parecem produzir textos mais longos e não necessariamente publicados como artigos mas também são importantes os capítulos de livros e livros, frequentemente assinados por apenas um pesquisador. Nessas áreas podem conviver mais de uma abordagem teórica ou várias escolas de pensamento. Não há, também, uniformidade nos métodos adotados, havendo espaço para métodos quantitativos, semelhantes às ciências exatas, métodos qualitativos em suas várias versões e o uso de diversas combinações. Um terceiro grupo, formado pelas áreas ligadas á tecnologia e às ciências aplicadas parecem seguir ainda outros padrões, onde relatórios e trabalhos apresentados em congresso gozam do mesmo prestígio que artigos científicos ou capítulos de livros nas outras áreas.

Cada área possui suas especificidades e maneiras diferentes de fazer pesquisa, bem como formas e maneiras de divulgação de suas pesquisas. Outro fator que pesa para as publicações da área das Ciências Sociais Aplicadas é que os pesquisadores das áreas de exatas e naturais publicam em inglês e em revistas internacionais, enquanto na área de sociais aplicadas, os pesquisadores publicam mais na sua língua materna e em seu país.

O grau de consolidação da área de conhecimento também é um fator influenciador. Nas áreas de ciências humanas e sociais, o conhecimento não está consolidado e então a pressão para se publicar é menor, o elenco de canais disponíveis para publicação é igualmente menor e a massa crítica necessária ao reconhecimento do que foi publicado está ainda em formação (SILVA; MENEZES; PINHEIRO, 2003, p. 195).

Como não há tanta pressão para publicar na área das Ciências Sociais Aplicadas, isso 
reflete no quantitativo inexpressivo de grupos de pesquisa ${ }^{2}$ no país, principalmente porque não existe uma cultura científica ou até mesmo uma recomendação "implícita ou explícita" dos órgãos que regulamentam os programas de pós-graduação sobre essa necessidade por publicar os resultados de determinada pesquisa em revistas de alcance internacional, ou seja, em inglês e/ou bem avaliada pelas bases de dados internacionais.

Nas áreas de ciências sociais e humanidades, a publicação em revista de padrão internacional é exceção e a falta de publicações nacionais regulares faz com que as mesmas não sejam selecionadas para serem analisadas pelos indexadores internacionais (entre os quais estão as publicações/bases de dados do ISI) (SILVA; MENEZES; PINHEIRO, 2003, p.214)

Para Rosa (2008), muitos pesquisadores brasileiros não se dedicam exclusivamente à pesquisa, principalmente devido à sobrecarga da pesquisa em si, pois demanda tempo e acaba impactando as demais atividades docentes, como as aulas, a orientação de teses e dissertações e a própria produção dos artigos desenvolvidos por esses docentes.

Luiz (2006) tece crítica sobre essa cobrança por quantificação da produção acadêmica em que, para ele

[...] a atual tendência pela quantificação como estratégia de avaliação de "qualidade" acadêmica, se por um lado a viabiliza operacionalmente, por outro, não nos deve cegar quanto às suas claras limitações. [...] o campo acadêmico impõe tantas dimensões e nuances de qualidade que os ideais de quantificação de qualquer avaliação, se não têm malogrado totalmente, têm, pelo menos, suscitado a justificada insatisfação de muitos (LUIZ, 2006, p. 301).

Conforme exposto, o objetivo deste artigo é analisar onde os docentes e consequentemente, pesquisadores dos cursos de Jornalismo do Estado do Tocantins publicam seus trabalhos científicos e como foi a produção acadêmica dos mesmos no período de 2006 a 2016 quando do funcionamento de três cursos: dois na capital Palmas e outro no interior, na cidade de Gurupi.

\section{Os cursos de Jornalismo no Tocantins}

O hoje, curso de Jornalismo da Universidade Federal do Tocantins (UFT), foi criado em 1996 por meio do Decreto n³32/96, do Governo do Estado do Tocantins, na então Universidade do Tocantins (Unitins).

Na Unitins, o então curso de Bacharelado em Comunicação Social foi criado pela Resolução Unitins nº 001/96, de 04 de novembro de 1996. O funcionamento foi autorizado pelo parecer n 076/00, publicado em Diário Oficial de 28 de agosto de 2000, n 965, página 20939 A criação do curso de Comunicação Social veio atender a demanda do mercado da comunicação que, a exemplo de outros setores econômicos, se encontrava em franca expansão, dada a criação recente do Estado da federação.

2Para dados sobre os grupos de pesquisa consultar a série histórica do Diretório dos Grupos de Pesquisa no Brasil. Disponivel em: http://lattes.cnpq.br/web/dgp 
A primeira estrutura curricular do curso de Comunicação Social foi autorizada pelo ConseIho Estadual de Educação do Tocantins, conforme parecer n 068/99 "Aprovação de grades curriculares e autorização para funcionamento do Curso de Comunicação Social", processo n 1999/2700/002024, aprovado em 04 de maio de 1999. O reconhecimento do curso foi feito pelo Conselho Estadual de Educação, por meio do Parecer n 306/2001, aprovado em 20/09/2001, processo n² 2001/2700/002379.

Em 2001, conforme dados do E-mec³, portal do Ministério da Educação e Cultura (MEC) que reúne dados de todas as instituições de ensino no país, foram criados também mais dois cursos de Comunicação Social - Habilitação em Jornalismo: no Centro Universitário Unirg em Gurupi e no CEULP/ULBRA em Palmas.

A UnirG, era denominada Faculdade de Filosofia e Ciências Humanas de Gurupi (FAFICH), mantida pela Fundação Educacional de Gurupi (FEG) no período compreendido entre 1985 a 1997, época em que eram ofertados apenas dois cursos de graduação: Direito e Pedagogia. Ainda sobre a Unirg, não há muitas informações oficiais em sua página na Internet e não foram encontradas dados disponíveis nos meios digitais.

O curso de Jornalismo do CEULP/ULBRA também iniciou suas atividades no ano de 2001 com o objetivo de estimular os alunos a estudar e compreender as novas demandas midiáticas, passando a dominar não só a técnica do "fazer jornalístico", mas também a reflexão, a crítica, a criatividade, a ética e a cidadania. O curso do CEULP/ULBRA foi autorizado pela Resolução CONSEPE nº 050, de 17/10/01 e reconhecido pela Portaria MEC nº 718, de 06/10/06.

Em 2003, com a criação da Universidade Federal do Tocantins, (UFT) em convênio assinado entre o Governo do Estado, a Unitins e o Governo Federal, o curso de Comunicação Social, bem como os demais cursos de graduação oferecidos pela Unitins, foram transferidos para a UFT. E, já transferido para a UFT, o curso de Comunicação Social foi recredenciado em agosto de 2005 pelo Conselho de Educação Superior - Inep/MEC.

Em 2013, com a instituição das Novas Diretrizes Curriculares, os cursos de Jornalismo passaram a constituir graduação dissociada da grande área da Comunicação Social, sendo necessária a reestruturação da concepção do curso e sua matriz curricular, ou seja, as três instituições que antes ofereciam o curso de Bacharel em Comunicação Social, agora ofertariam Bacharel em Jornalismo.

Com isso, os quadros de docentes das Instituições de Ensino Superior como um todo sofreram consideráveis transformações, havendo então a obrigatoriedade de formação mínima de mestrado para a docência na graduação e incentivando a efetivação de professores doutores em todas as áreas. Acompanhando essas transformações, surgem então várias adequações dos cursos para essa nova realidade, sendo uma delas a reestruturação de seus projetos pedagógicos.

\section{Procedimentos metodológicos}

A pesquisa tem caráter exploratório. Caracterizada como do tipo documental, estudo de caso, procedimentos concomitantes e métodos mistos (CRESWELL, 2007). O universo da 
pesquisa foi constituído por 35 docentes do curso de Jornalismo das Instituições de Ensino Superior do Estado do Tocantins: Universidade Federal do Tocantins (UFT), Centro Universitário UnirG e Centro Universitário Luterano de Palmas (Ceulp/Ulbra).

Após identificar as Instituições de Ensino Superior, realizou-se o levantamento dos docentes efetivos/titulares das instituições selecionadas por meio de relação fornecida pelas coordenações dos cursos, bem como informações nos sites institucionais. Foram excluídos desta pesquisa os docentes convidados ou voluntários das instituições que ministravam disciplinas temporárias.

O foco da pesquisa foi identificar o destino das publicações científicas produzidas pelos docentes nos últimos dez anos de produção acadêmica, dentro das categorias estabelecidas pelo Conselho Nacional de Desenvolvimento Científico e Tecnológico (CNPq) por meio da Plataforma Currículo Lattes, sendo elas: Artigos, Livros/Capítulos de Livros, Anais de Congresso (Trabalhos completos), Resumos em Congressos e Apresentação de Trabalhos.

O procedimento adotado nesta pesquisa documental foi a coleta de dados em fonte primária, neste caso o Currículo Lattes de cada docente que é público e disponibilizado pelo CNPq na Plataforma Lattes. A coleta de dados aconteceu no dia 24 de novembro de 2016.

O Currículo Lattes se tornou um padrão nacional no registro da vida pregressa e atual dos estudantes e pesquisadores do país, e é hoje adotado pela maioria das instituições de fomento, universidades e institutos de pesquisa do País. Por sua riqueza de informações e sua crescente confiabilidade e abrangência, se tornou elemento indispensável e compulsório à análise de mérito e competência dos pleitos de financiamentos na área de ciência e tecnologia (CNPQ, 2016).

Com relação à atualização das informações coletadas nos currículos dos docentes, algo que chamou a atenção foi a desatualização dos currículos por mais de anos, casos em que a última atualização, principalmente de publicação de alguma produção científica, datava de 2009, conforme mostra a Tabela 1.

Tabela 1. Última atualização do Currículo Lattes dos docentes de Jornalismo no Tocantins

\begin{tabular}{|c|c|}
\hline Ano de Atualização & $\begin{array}{c}\text { Quantidade de } \\
\text { Docentes }\end{array}$ \\
\hline 2016 & 26 \\
\hline 2015 & 01 \\
\hline 2014 & 04 \\
\hline 2013 & 03 \\
\hline 2009 & 01 \\
\hline
\end{tabular}

Fonte: Extração de dados da base de Currículo Lattes em 24/17/2016.

Do quantitativo de currículos analisados, sendo 35 ao todo, temos: 20 docentes doutores, 08 mestres e 07 especialistas conforme demonstra a Tabela 2, ratificando assim que há um corpo docente apto para desenvolver mais pesquisas, uma vez que são doutores. 
Tabela 1. Formação/Titulação dos Docentes de Jornalismo (Tocantins)

\begin{tabular}{|l|c|}
\hline \multicolumn{1}{|c|}{ Formação/Titulação } & $\begin{array}{c}\text { Quantidade de } \\
\text { Docentes }\end{array}$ \\
\hline Doutorado & 20 \\
\hline Mestrado & 05 \\
\hline Especialização Lato Sensu & 07 \\
\hline
\end{tabular}

Fonte: Extração de dados da base de Currículo Lattes em 24/77/2016.

Do total de produção científica dos docentes dos cursos pesquisados neste artigo, têm-se 729 publicações no período analisado. Conforme exposto no Gráfico 1 e com os dados consolidados de onde publicaram os docentes de Jornalismo do Tocantins nesses últimos dez anos, ou seja, entre 2006 a 2016, identificou-se que existe preferência para "Apresentação de Trabalhos em Congressos Científicos" com 238 publicações até o mês de novembro de 2016. Seguida por publicações em "Anais de Congressos (trabalhos completos)" com 159 publicações no período analisado.

\section{Gráfico 1. Produção Científica dos Docentes de Jornalismo (Tocantins)}

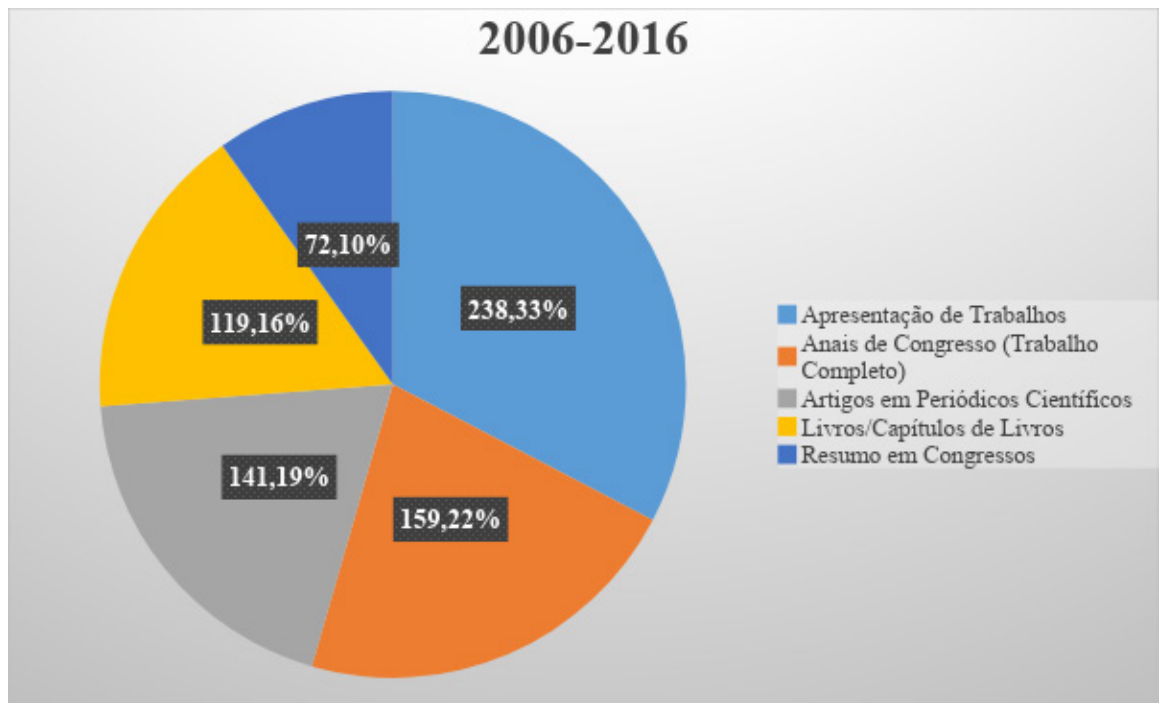

Fonte: Extração de dados da base de Currículo Lattes em 24/71/2016.

Analisando ainda o Gráfico 1, temos a publicação de "Artigo Científico" em terceira posição no registro dos docentes para divulgação científica com 141 publicações nesses 10 anos. Na quarta posição obteve-se, conforme dados dos currículos dos docentes, a publicação de "Livros e/ou Capítulos de livros" com 119 obras publicadas nesses dez anos, o quê pode-se considerar um expressivo número para a área. E, em última posição, tem-se a publicação de resumos em congressos com 72 publicações.

Percebe-se então, que houve uma preferência dos docentes de Jornalismo para a participação em eventos científicos, principalmente por cerca de 55\% das publicações estarem nos eventos científicos da área, diferentemente de outras áreas da ciência como as exatas e naturais que publicam em periódicos. 


\section{Considerações finais}

Com base nos dados apresentados após a extração dos dados de produção dos docentes, bem como nos posicionamentos dos autores, percebe-se que não há uma "regra" a ser seguida sobre onde fazer uma publicação científica, pois áreas como Ciências Sociais Aplicadas, e nela encontramos o Jornalismo, são tendentes à divulgação cientifica em Congressos, Seminários, Colóquios e demais eventos dessa natureza. Apresentar o trabalho e compartiIhar a experiência vivida durante o desenvolver da pesquisa, demonstra ser a preferência dos professores aqui pesquisados, uma vez que ele leva seu trabalho para análise dos pares.

Não é pretensão deste mapeamento estabelecer qual melhor lugar para publicação científica, uma vez que cada área tem seus caminhos. Porém, um questionamento surge: como considerar o que é uma publicação de peso? Por que publicar em periódicos é mais expressivo do que quê publicar um livro? Essas exigências por mais publicações de qualidade e em periódicos de impacto por parte da Coordenação de Aperfeiçoamento de Pessoal de Nível Superior (Capes) aos programas de pós-graduação stricto sensu e consequentemente aos docentes faz com que haja uma cobrança maior por quantificações maiores.

Quando analisamos o Gráfico e as tabelas apresentadas acima, pergunta-se: por que os professores pararam de atualizar seus currículos? Até porque subentende-se que se são docentes de cursos superiores estão produzindo ciência e deveriam publicar algum resultado? Por que a preferência por congressos e não revistas científicas? Geralmente os congressos publicam com maior rapidez para atrair quórum de participantes para os Grupos de Trabalho e consequentemente, fortalecer o evento. Já os periódicos, por exemplo, demoraram entre seis meses a um ano para emitir um parecer se aquele trabalho foi aceito ou não.

Por fim, a discussão que este trabalho pretendeu levantar é: onde publicam os docentes do curso de Jornalismo do Estado do Tocantins? E como resposta obteve-se que as apresentações de trabalhos e a publicação do trabalho completo em congressos científicos, sobressaem-se ao relacionarmos com a publicação de artigos em periódicos no período de 2006 a 2016.

Como sugestão para seguimento da pesquisa, é necessário como coleta de dados, entrevistas com uma amostragem dos docentes, para que se possa então entender as motivações em publicar (ou não) em outros "meios". E, dos questionamentos da contemporaneidade docente, fica-se então com o dilema: publicar ou perecer?

\section{Referências}

BRASIL. Ministério da Educação. Resolução n 1, de 27 de setembro de 2013. Institui as Diretrizes Curriculares Nacionais para o curso de graduação em Jornalismo, bacharelado, e dá outras providências. Resolução CNE/CES 1/2013. Diário Oficial da União, Brasília, $1^{\circ}$ de outubro de 2013 - Seção 1 - p. 26

CENTRO UNIVERSITÁRIO LUTERANO DE PALMAS - CEULP/ULBRA. Jornalismo. Disponível em <http://www.ulbra.br/palmas/graduacao/presencial/jornalismo/bacharelado/> Acesso em 30 de Nov 2016

CNPQ. A Plataforma Lattes. Disponível em <http://lattes.cnpq.br/> Acesso em 30 de Nov 2016. 
CRESWELL, Jhon W. Projeto de Pesquisa: métodos qualitativo, quantitativo e misto. 2 ed Porto Alegre: Artmed, 2007.

LUIZ, R. R. Avaliação de produtividade acadêmica: uma proposta de quantificação. Revista Brasileira de Pós-Graduação, v.3, n.6, p. 300-312, dez. 2006.

MUELLER, Suzana Pinheiro Machado. A publicação da ciência: áreas científicas e seus canais preferenciais. DataGramaZero: Revista de Ciência da Informação, v. 6, n. 1, fev. 2005. Disponível em: <http://inseer.ibict.br/ancib/index.php/tpbci/article/view/11/9>. Acesso em: 1 mar. 2016.

ROSA,Alexandre Reis. "Nós e os índices": um outro olhar sobrea pressão institucional por publicação. Rev. adm. empres., São Paulo, v. 48, n. 4, p. 108-174, Dec. 2008. Disponívelem<http://www. scielo.br/scielo.php?script=sci_arttext\&pid=S0034-75902008000400010\&lng=en\&nrm=iso> Acesso em 04 Mai 2016. http://dx.doi.org/10.1590/\$0034-75902008000400010.

SILVA, Edna Lúcia da, MENEZES, Estera Muszkat, PINHEIRO, Liliane Vieira. Avaliação da Produtividade Científica dos Pesquisadores nas Áreas de Ciências Humanas e Sociais Aplicadas. In: Informação e Sociedade: Estudos, João Pessoa, v.13, n.2, p. 193-222, jul/dez, 2003. Disponível em <http://www.ies.ufpb.br/ojs/index.php/ies/article/view/97/0>. Acesso em 09 mar. 2016

SOUZA, Francisco das Chagas de. Comunicação científica no Brasil: criação e evolução da Revista Encontros Bibli.. Informação \& Informação, [S...], v. 13, n. 1, p. 140-158, jul. 2008. ISSN 1981-8920. Disponível em: <http://www.uel.br/revistas/uel/index.php/informacao/article/view/1804>. Acesso em: 01 dez. 2016. doi:http://dx.doi.org/10.5433/1981-8920.2008v13n1p140.

UFT - UNIVERSIDADE FEDERAL DO TOCANTINS. Bacharelado em Jornalismo. Disponível em < http://ww2.uft.edu.br/ensino/graduacao/cursos/10748-comunicacao-social-jornalismo> Acesso em 30 de Nov 2016.

UNIRG - CENTRO UNIVERSITÁRIO UNIRG. Jornalismo. Disponível em < http://www.unirg edu.br/cursos/graduacao01/jornalismo.html> Acesso em 30 de Nov 2016.

Recebido: 13/07/2018 Aceito: 26/09/2018 